\title{
BIOSSEGURANÇA: CONHECIMENTO E ADESÃO PELOS PROFISSIONAIS DO CORPO DE BOMBEIROS MILITAR DE MINAS
}

\author{
Biosafety: knowledge and compliance by fire military brigade of minas gerais \\ Bioseguridad: conocimiento y adhesión en el cuerpo de bomberos militar de minas \\ gerais, uno estudio transversal
}

Adriana Cristina de Oliveira ${ }^{1}$
Juliana Ladeira Garbaccio $^{4}$

Bruno César Amorim Machado ${ }^{2}$

Quésia Souza Damasceno ${ }^{5}$
Camila Sarmento Gama ${ }^{3}$

\section{RESUMO}

Objetivou-se identificar o conhecimento e a adesão às recomendações de biossegurança entre profissionais do Corpo de Bombeiros Militar de Minas Gerais de um município da Região Metropolitana de Belo Horizonte, Minas Gerais. Realizou-se um estudo transversal de abordagem quantitativa. Na coleta de dados foi utilizado um questionário estruturado composto de questões sobre conhecimento e atitudes relativos à biossegurança, fatores dificultadores ao uso de equipamentos de proteção individual e ocorrência de acidentes com material biológico. 0 conhecimento sobre a higienização das mãos foi verificado em 84,8\% dos profissionais; $69,7 \%$ desconheciam a ação do álcool a $70 \%$. 0 capote foi o equipamento de proteção individual mais difícil de ser utilizado. Os militares não sofreram acidente com material biológico, dado semelhante aos demais da literatura. Pretende-se provocar a reflexão dos profissionais da área e instituições responsáveis quanto à reavaliação da proposta relacionada à formação desses trabalhadores em biossegurança e saúde ocupacional.

Palavras-chave: Exposição a agentes biológicos. Assistência pré-hospitalar. Precauções universais. Riscos ocupacionais.

\begin{abstract}
It was aimed to identify knowledge and adherence of biosafety recommendations by military Firefighters of Minas Gerais from a city in the metropolitan area of Belo Horizonte, Minas Gerais. A cross-sectional study of quantitative approach was held. The study instrument was a structured questionnaire that included questions about knowledge and attitudes related to biosafety, complicating factors for adherence to standard precautions and incidence of accidents involving biological materials. It was demonstrated knowledge about hand hygiene recommendation in $84,8 \%, 69,7 \%$ didn't know the way of alcohol $70 \%$ action. The scrubs were cited as the most difficult personal protective equipment to be used. The militaries haven't had any accident with biological material, similar data to other from literature. It is intended to provoke reflection of the professionals in the area and institutions responsible about the reassessment of the proposal related to the formation of these workers in biosafety and occupational health.
\end{abstract}

Keywords: Exposure to Biological Agents. Prehospital Care. Universal precautions. Occupational Risks.

\section{Resumen}

Tuvo como objetivo identificar el conocimiento y la adhesión de las recomendaciones de bioseguridad entre profesionales del Cuerpo de Bomberos Militares de Minas Gerais, de un municipio de la región metropolitana de Belo Horizonte, Minas Gerais. Se realizó un estudio transversal de enfoque cuantitativo. Para la recolección de datos fue utilizado un cuestionario estructurado con preguntas sobre conocimientos y actitudes relacionadas a bioseguridad, factores que dificultan el uso de equipos de protección personal y accidentes con material biológico. El conocimiento sobre higiene de las manos fue observado en $84,8 \%$ de los profesionales, $69,7 \%$ desconocían la forma de acción del alcohol 70\%. El manto fue el equipo de protección personal más difícil de usar. Los militares no han sufrido acidentes con material biologico, datos similares a los de la literatura. Tuvo como intención provocar la reflexión de los profesionales y de las instituciones responsables, cuanto a la revisión de la propuesta relacionada con la formación de estos trabajadores en bioseguridad y salud ocupacional.

Palabras clave: Exposición a agentes biológicos. Atención Prehospitalaria. Precauciones universales. Riesgos Laborales.

\footnotetext{
${ }^{1}$ Enfermeira. Pós-doutora pela New York University, Estados Unidos. Professora Associada da Escola de Enfermagem da Universidade Federal de Minas Gerais. Orientador. Líder do Núcleo de Estudos e Pesquisas em Infecção Relacionada ao Cuidar em Saúde (NEPIRCS)/CNPq. Belo Horizonte-MG. Brasil. E-mail: adrianacoliveira@gmail.com; ²Enfermeiro graduado pela Escola de Enfermagem da Universidade Federal de Minas Gerais. Voluntário. Membro do Núcleo de Estudos e Pesquisas em Infecção Relacionada ao Cuidar em Saúde. Belo Horizonte-MG. Brasil. E-mail: brunochedidsports@yahoo.com.br; ${ }^{3}$ Enfermeira graduada pela Escola de Enfermagem da Universidade Federal de Minas Gerais. Membro do Núcleo de Estudos e Pesquisas em Infecção Relacionada ao Cuidar em Saúde. Belo HorizonteMG. Brasil. E-mail: camilasarmento@ig.com.br; ${ }^{4}$ Doutoranda em Enfermagem pela Universidade Federal de Minas Gerais, Professora da PUC-MG. Membro do Núcleo de Estudos e Pesquisas em Infecção Relacionada ao Cuidar em Saúde. Belo Horizonte-MG. Brasil. E-mail: julade@gmail.com; ${ }^{5}$ Doutoranda em Enfermagem pela Universidade Federal de Minas Gerais. Membro do Núcleo de Estudos e Pesquisas em Infecção Relacionada ao Cuidar em Saúde. Belo Horizonte-MG. Brasil. E-mail: qdamasceno@yahoo.com.br
} 


\section{INTRODUÇÃO}

0 Atendimento Pré-hospitalar (APH) refere-se ao serviço prestado a vítimas clínicas ou traumáticas antes da chegada ao estabelecimento de saúde de referência mais próximo, podendo ser realizado por profissionais treinados, sejam médicos ou não ${ }^{1}$. A finalidade deste tipo de atendimento é agilizar a assistência no intuito de manter a vida e/ou minimizar as possíveis sequelas à saúde da vítima ${ }^{1}$.

Os socorristas que atuam nas viaturas de resgate do Corpo de Bombeiros Militar de Minas Gerais (CBMMG), embora sejam profissionais não médicos, recebem o treinamento de salvamento e suporte básico de vida (SBV), capacitando-se a prestar primeiros socorros às vítimas em diversas situações, mas não se habilitando para a realização de procedimentos invasivos. Entretanto, ainda que não realizem tais procedimentos no desempenho de suas atividades, esses profissionais se expõem com grande frequência a materiais biológicos das vítimas, constituíndo-se, assim, elevado risco ocupacional ${ }^{1-2}$.

Os acidentes ocupacionais podem decorrer das características do serviço de APH móvel como: espaço limitado dentro das viaturas, com ventilação restrita que dificulta a recirculação do ar; e movimento do tráfego com trepidações, solavancos, propulsão dos corpos pela energia cinética decorrente das acelerações ou desacelerações dos veículos e curvas em alta velocidade 1 . Além disso, o atendimento de emergência prestado exige destreza, habilidade e agilidade, fatores desencadeadores de um elevado nível de estresse que, consequentemente, podem favorecer a ocorrência de acidentes ocupacionais. Dentre esses acidentes, destaca-se 0 acidente com o Material Biológico Potencialmente Contaminado (MBPC) ${ }^{1}$.

Os riscos ocupacionais relacionados aos acidentes por MBPC, nos serviços do APH móvel, podem estar relacionados ao contato direto com sangue, secreções, excreções e outros fluidos corpóreos infectados ou não; ao contato indireto por meio de respingos de sangue, secreções, excreções e outros fluidos corpóreos na pele e/ ou mucosa; e à transferência de patógenos por meio de materiais e equipamentos contaminados, aerossóis e fômites ${ }^{3}$.

Com o intuito de minimizar o contato com o material biológico e proteger os profissionais expostos a eles, em 1996, o Centers for Disease Control and Prevention (CDC), nos Estados Unidos, editou o Guia de Precaução e Isolamento com as denominadas precauçõespadrão, recomendações a serem adotadas no atendimento de todo e qualquer paciente, independente de seu diagnóstico, que foram mantidas e reforçadas na revisão deste guia em 2007. Dentre as medidas preconizadas incluem-se a higienização das mãos, o uso de equipamento de proteção individual (EPI), a vacinação contra a hepatite
B e o descarte adequado de materiais perfurocortantes ${ }^{4}$. Dessa forma, a não adesão a essas precauçõespadrão pode configurar uma maior exposição do profissional, favorecendo a ocorrência do acidente e podendo acarretar ausências ao trabalho, temporárias ou permanentes, como licenças médicas e até casos de invalidez.

No entanto, a adesão a essas medidas depende, sobremaneira, do conhecimento sobre tais medidas, por parte dos trabalhadores de saúde em todos os níveis de atenção, inclusive no atendimento pré-hospitalar.

Nesse contexto, ainda são escassos os estudos acerca do risco para acidentes de trabalho envolvendo profissionais do corpo de bombeiros no APH, no que se refere à determinação do seu conhecimento e atitudes relacionados à biossegurança, comparativamente aos outros serviços móveis de urgência.

Assim, pelas características do trabalhador do resgate do CBMMG e considerando a ausência de pesquisas neste segmento, torna-se de grande relevância uma avaliação do conhecimento desses profissionais em relação à biossegurança e adesão às medidas de precaução, a fim de aprimorar as políticas de formação e capacitação destes profissionais, enfocando a saúde deste trabalhador e a qualidade da assistência por eles prestada ${ }^{1,5}$.

Nesse sentido, o objetivo deste trabalho foi identificar o conhecimento e adesão dos profissionais do APH do corpo de bombeiros, acerca das recomendações de biossegurança, dentre elas as precauções-padrão e o uso de EPI, além de identificar a incidência de acidente com material biológico entre estes profissionais.

\section{MÉTODO}

Realizou-se uma pesquisa de corte transversal e de abordagem quantitativa com os profissionais militares atuantes no Corpo de Bombeiros Militar de em um município da Região Metropolitana de Belo Horizonte durante três dias consecutivos do mês de novembro de 2010. A amostra deste estudo foi composta por trinta e três profissionais.

Para a para coleta de dados utilizou-se um questionário anônimo, estruturado, autoaplicável. Abordaram-se aspectos referentes a dados demográficos, questões sobre conhecimento e adesão às recomendações de biossegurança, fatores dificultadores para a baixa ou não adesão ao uso dos EPI, além de determinação da incidência de acidentes com material biológico ocorridos no ano de 2009, por meio do questionamento ao militar se nos últimos doze meses sofreu algum acidente ocupacional envolvendo material biológico (sangue, saliva, sêmen, secreção vaginal ou do ânus, líquido amniótico) durante o APH. 0 instrumento foi avaliado por especialistas na área de infecções relacionadas ao cuidar em saúde quanto a pertinência e abrangência do conteúdo das questões com a finalidade de 


\section{Biossegurança no Corpo Bombeiro Militar}

avaliar a coerência do instrumento de coleta de dados com a proposta do estudo.Após a assinatura do TCLE, o instrumento de coleta de dados foi, então, apresentado por um dos pesquisadores aos participantes do estudo durante o seu período de trabalho, com as devidas orientações para o preenchimento completo do mesmo. Após esta etapa, os dados obtidos foram digitados e analisados com o auxílio do software estatístico Statistical Package for the Social Sciences (SPSS $®$ ) Versão13.0.

Para o tratamento dos dados realizaram-se análise descritiva, distribuição absoluta e relativa e análise univariada.

Os sujeitos convidados a participar desta pesquisa assinaram o Termo de Consentimento Livre e Esclarecido (TCLE), atendendo a Resolução do Conselho Nacional de Pesquisa 196/96 para pesquisa envolvendo seres humanos. 0 presente projeto é parte de um projeto maior intitulado Atendimento pré-hospitalar público de Belo Horizonte: Uma análise da adoção às medidas de precaução pela equipe multiprofissional, aprovado pelo Comitê de Ética em Pesquisa da Universidade Federal de Minas Gerais Parecer $n^{0}$ ETIC 458/05 e pelo Comando Operacional de Bombeiros (COB) No 7262/09 - COB, responsável por todos os batalhões do Estado de Minas Gerais.

\section{RESULTADOS}

Faziam parte do quadro da unidade do corpo de bombeiros, campo deste estudo, 45 militares; entretanto, retirando aqueles que se encontravam de férias, folgas ou licenças médicas, 33 foram abordados durante o período de coleta de dados e todos consentiram na participação. Desses, $100 \%$ pertenciam ao sexo masculino, a média de idade foi de 29 anos ( 19 a 48 anos) e segundo a patente destes profissionais, $78,8 \%(26)$ se classificavam como cabo ou soldado e $18,2 \%$ (6), subtenente ou sargento.

0 tempo de duração do Curso de Formação de Soldados para ingressar no CBMMG foi de seis meses para 69,2\% (23) dos participantes. Quanto à formação regular, $84,8 \%$ (28) não tinham nenhum curso de graduação, 78,8\% (26) realizaram o Curso de Formação de Soldados ou Curso Técnico em Segurança Pública. Em relação à experiência profissional, 54,5\% (18) dos trabalhadores tinham tempo de serviço na instituição inferior a dois anos (amplitude $=$ sete meses a vinte e cinco anos).

Ao serem questionados acerca do aprendizado, durante a formação profissional, em alguma disciplina ou palestra que abordasse os temas biossegurança ou segurança da vítima, $51,5 \%$ (17) afirmaram que receberam essas informações. Desses, 88,2\% (15) obtiveram essa informação entre 2009 e 2010. Entretanto, 45,5\% (15) declararam não ter recebido nenhuma informação sobre o assunto. 0 meio mais utilizado para atualização profissional referido foi a participação em treinamentos durante a jornada de trabalho $(45,4 \%$ - 15), seguida da utilização do computador e pesquisas em sites eletrônicos por conta própria $(42,4 \%$ - 14).

Ao analisar o conhecimento dos militares quanto à recomendação de higienização das mãos (HM) com água e sabão, 84,8\% (28) responderam corretamente que esta deve ocorrer antes e após o contato com a vítima e antes e após remover luvas estéreis ou não estéreis. No entanto, no que diz respeito ao conhecimento da atividade antisséptica com álcool a $70 \%, 69,7 \%$ (23) deles responderam equivocadamente que o álcool é utilizado devido a sua capacidade de esterilização, seguidos de 18,7\% (6) que afirmaram que sua utilização se deve por inibição do crescimento bacteriano. Ainda em relação à friç̧ão das mãos com álcool a 70\%, 54,5\% (18) informaram corretamente que este é recomendado mesmo na ausência de sujidade visível nas mãos e $22,1 \%$ (7) não sabiam a sua recomendação.

No tocante ao descarte dos resíduos gerados após os atendimentos, a referência ao uso do saco plástico branco leitoso para o acondicionamento dos resíduos foi mencionado como recomendação adequada para $60,6 \%$ (20) dos participantes.

Quando questionados acerca da ocorrência de acidente com exposição a material biológico, verificouse que estes não aconteceram para 90,9\% (30) dos entrevistados e a questão não foi respondida por $9,1 \%$ (3) dos demais participantes.

Em relação à realização de exames sorológicos após acidente de trabalho, 57,6\% (19) informaram que devem ser feitos testes sorológicos para HIV, hepatite B e hepatite $\mathrm{C}$ no dia do ocorrido, três, seis meses e um ano após o acidente e $36,4 \%$ (12) afirmaram que esses mesmos testes deveriam ser realizados apenas uma semana após 0 ocorrido.

Quanto à utilização de luvas descartáveis durante procedimentos com risco de se exporem a líquidos corporais da vítima, 93,9\% (31) relataram sempre utilizá-las, $3 \%$ (1), na maioria das vezes, e 3\% (1) referiram não utilizá-las.

Ao serem questionados sobre a dificuldade de utilização de equipamentos de proteção individual, destacou-se que 42,4\% (14) dos entrevistados não registraram nenhuma dificuldade na utilização de qualquer um dos EPI, 15,2\% (5) apresentaram dificuldade de usar o capote/avental e 9,1\% (3) dos militares relataram a dificuldade de usar máscara (Tabela 1). 
Tabela 1. Distribuiç̧ão dos equipamentos de proteção individual quanto à dificuldade de utilização pelos bombeiros militares. Região Metropolitana de Belo Horizonte, 2010

\begin{tabular}{lrr}
\hline EPI & Frequência & Porcentagem \\
\hline Nenhuma dificuldade & 14 & 42,4 \\
Capote/avental & 5 & 15,2 \\
Máscara facial & 3 & 9,1 \\
Óculos de segurança & 2 & 6,1 \\
Máscara facial e óculos de segurança & 2 & 6,1 \\
Óculos de segurança e capote/avental & 2 & 6,1 \\
Luva descartável e capote/avental & 1 & 3,0 \\
Máscara facial e capote/avental & 1 & 3,0 \\
Não respondeu & 3 & 9,1 \\
\hline Total & 33 & 100,0 \\
\hline
\end{tabular}

Quanto ao uso de luva descartável, embora apenas um indivíduo tenha relatado a dificuldade de usá-la inicialmente, oito $(24,2 \%)$ posteriormente informaram que o motivo da dificuldade de usá-las se deve à indisponibilidade de seu tamanho na viatura. Essa incoerência pode ser explicada pelo fato de que, no questionário, a pergunta acerca da dificuldade de utilização de algum EPI era seguida da pergunta dos motivos para a dificuldade de utilizá-los, sendo que muitos dos participantes só recordaram de algumas dificuldades ao ler a segunda pergunta e muitas vezes esqueciam-se de completar a primeira pergunta sobre qual seria esse EPI (anexo 1). De maneira semelhante, a dificuldade do uso da máscara facial foi mencionada por seis trabalhadores, e um número superior (13) afirmou ter dificuldade de usá-la devido à sensação de sufocamento, indisponibilidade na unidade, desconforto, esquecimento, dificuldade de comunicação com a vítima e embaçamento das lentes dos óculos. Quanto aos óculos de proteção, a dificuldade de sua utilização esteve relacionada principalmente ao fato de seu uso ser coletivo, isto é, os óculos não são entregues individualmente para cada um usar o seu, mas sim ficam disponibilizados para todos em um local espećíico por viatura, conforme observado no Figura 1.

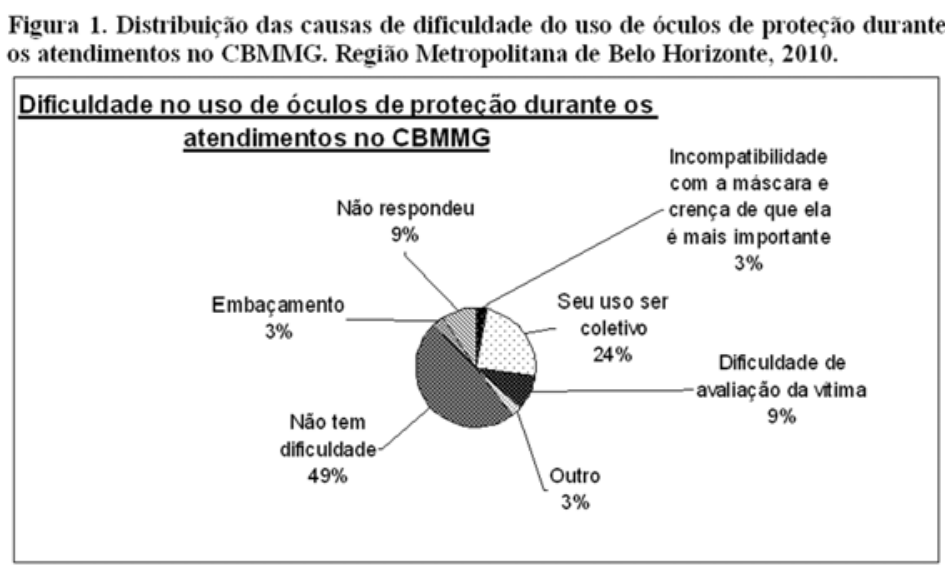

Dentre os motivos alegados como dificultadores para a utilização do capote/avental estão: indisponibilidade na viatura $27,3 \%$ (9), pouco tempo $6,1 \%$ (2), esquecimento $6,1 \%$ (2), crença de irrelevância do uso 3\% (1).
Para o levantamento do estado sorológico dos militares do CBMMG, estes foram questionados quanto ao número de doses recebidas para hepatite $B$, sendo que doze $(36,4 \%)$ não souberam responder a esta pergunta, Figura 2.

Figura 2. Relaçāo do número de doses recebidas para hepatite B. Região Metropolitana de Belo Horizonte, 2010.

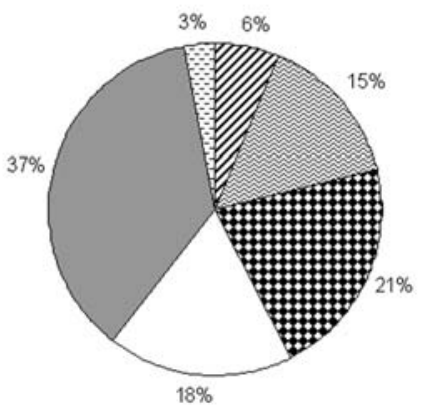


No que se refere ao conhecimento do risco de desenvolver uma infecção após o contato de fluidos corporais da vítima com a mucosa ocular do profissional, 75,8\% (25) alegaram existir esse risco se a vítima for portadora de alguma doença infecciosa transmitida pelo sangue. Quanto às doenças possivelmente transmitidas devido à natureza do trabalho do APH, 93,9\% (31) indicaram a AIDS, hepatites B e C. E essa mesma porcentagem também respondeu corretamente que as precauções-padrão consistiam na utilização de equipamentos de proteção individual (óculos, máscara, luvas, gorro, capote e sapatos impermeáveis e fechados), lavagem das mãos, vacinação contra hepatite $B$ e descarte do material perfurocortante em recipiente de paredes rígidas.

Entre as soluções utilizadas para a limpeza das superfícies da viatura com presença de sujidade por material biológico, foram relacionados o uso de água oxigenada a $3 \%$ ou água e sabão (60,7\%), água e sabão seguida de álcool a 70\% $(12,1 \%)$, uso de álcool a $70 \%$ ou hipoclorito de sódio a $1 \%$ $(12,1 \%)$, e hipoclorito de sódio $(9,1 \%)$.

\section{DISCUSSÃO}

0 predomínio do sexo masculino no presente trabalho corrobora outros estudos envolvendo o atendimento préhospitalar em todo Brasil ${ }^{1,7}$. Esse resultado entre os bombeiros militares pode ser explicado pelo fato de que, historicamente, os ingressantes na carreira militar deveriam ser homens hígidos para melhor atender às demandas do serviço, que representavam riscos e exigiam muitos esforços físicos, trabalho esse inapropriado para mulheres. Assim, não existiam mulheres trabalhando entre os militares estaduais até 1981. Após essa data, elas passaram a corresponder a $20 \%$ do efetivo recrutado e, atualmente, $30 \%^{8}$.

A constatação de que quinze $(45,5 \%)$ militares não receberam nenhuma informação sobre biossegurança durante os cursos de formação que os capacitaram é preocupante, visto que estão expostos com frequência a material biológico e, consequentemente, apresentam risco de aquisição de microorganismos causadores de infecções durante 0 atendimento da vítima e, por isso, precisam se prevenir.

$\mathrm{Na}$ análise do programa do curso de Técnico em Emergências Médicas ministrado em todos os cursos de formação do CBMMG $^{9}$, a única menção à biossegurança se encontra em uma ementa com a seguinte descrição:

...aspectos emocionais do cuidado de emergência, combate 0 estresse, aborda a introdução aos questionamentos aos pacientes em ocorrências críticas, a segurança do cenário, isolamento de fluidos corporais, equipamento de proteção individual e precauções de segurança que possam assegurar o desempenho prático do socorrista ${ }^{9: 3}$.
De acordo com a definição que se apresenta para os cursos de formação dos militares, especificamente voltados para o aspecto da biossegurança, constata-se a ausência do detalhamento de seus aspectos e nuances em relação ao risco desta clientela, bem como a exploração desta temática em profundidade, que envolve a complexidade do atendimento visando a valorização das recomendações de boas práticas e sua compreensão, impacto e relevância durante 0 atendimento, visando a assistência em saúde, em qualquer de suas esferas: prevenção de doenças e agravos, promoção e recuperação da saúde.

Outro ponto relevante se refere à contaminação frequente das ambulâncias ou viaturas por material biológico durante 0 transporte de vítimas, tornando imprescindível a realização da desinfecção das mesmas. 0 uso de água oxigenada, mencionado por vinte $(60,6 \%)$ participantes visando à desinfecção das superfícies e equipamentos na presença de material biológico, não é recomendado. 0 peróxido de hidrogênio, popularmente conhecido como água oxigenada, decompõe-se rapidamente quando em contato com a enzima catalase encontrada no sangue e tecidos, liberando oxigênio. Este efeito pode ser reduzido na presença de matéria orgânica ${ }^{10}$. Dessa forma, sua utilização por meio da fricção, objetivando a desinfecção de equipamentos e superfícies na presença de material biológico, pode não apresentar o efeito desejado, justificando o abandono de sua prática nas instituições da saúde.

Recomenda-se, no entanto, para os equipamentos não críticos (termômetros, superfícies externas dos estetoscópios dentre outros), na ausência de instruções do fabricante, apenas limpeza, seguida de desinfecção intermediária, com a eliminação das formas bacterianas vegetativas, mas não dos esporos. Para estes equipamentos são usualmente utilizados o álcool etilico, ou isopropílico, na concentração entre $60 \%$ e $90 \%$ (v/v). E, para as superfícies como piso, paredes, bancadas, mesas e demais estruturas, é necessária a limpeza, sendo indicado o uso de desinfetantes apenas quando da presença de matéria orgânica ${ }^{10-11}$.

Para a lavagem das mãos, a maioria dos entrevistados demonstrou conhecimento acerca desta recomendação, consoante com outros estudos ${ }^{7}$. De acordo com o Manual de higiene das mãos (HM) na assistência à saúde da Organização Mundial de Saúde (OMS) de 2009, a HM deve ser feita com água e sabão antes e após o contato com o paciente e antes e após remover luvas estéreis e não estéreis entre outras situações ${ }^{12}$. Trata-se de um procedimento simples e altamente eficaz, que tem seu aspecto emocional e psicológico fortemente relacionado principalmente para profissionais do APH, que não possuem condições e infraestrutura adequadas durante a assistência prestada. Portanto, a valorização deste ato deve ser intensificada na chegada da viatura no local de espera para novos atendimentos, denominado prontidão de incêndio. 
No que diz respeito à atividade antisséptica do álcool a 70\%, chama atenção a compreensão equivocada de sua finalidade, demonstrada por 69,7\% (23) dos participantes, seja por interpretação ou desconhecimento dos conceitos de esterilização, assepsia, desinfecção e antissepsia. De acordo com o CDC, a esterilização é um processo em que ocorre a destruição ou eliminação de todas as formas microbianas de vida por meio de métodos físicos ou químicos, ação não realizada pelo álcool a 70\%. A desinfecção é o processo capaz de eliminar vários ou todos os micro-organismos patogênicos, exceto esporos bacterianos. Ela é realizada no ambiente e em objetos inanimados. A assepsia da pele é o termo utilizado para designar a prevenção do contato com o micro-organismo ${ }^{10}$.

Além disso, segundo o Manual de HM, a atividade antimicrobiana do álcool advém de sua habilidade de desnaturação das proteínas de alguns vírus, bactérias e fungos, por isso ele é recomendado para antissepsia, não devendo ser utilizado em mãos sujas ou visivelmente contaminadas com material proteico, por exemplo, o sangue ${ }^{12}$, devido ao risco de redução da sua eficácia.

No que se refere ao descarte dos resíduos gerados do APH, apesar de 60,6\% (20) relatarem o uso de saco plástico branco leitoso devidamente identificado, essa porcentagem ainda é insatisfatória, pois o acondicionamento adequado do lixo é uma forma de prevenir e controlar possíveis contaminações. A prática incorreta tem sido apontada em uma amostra semelhante ao do presente estudo, de profissionais do Corpo de Bombeiros, em que se detectou a presença de luvas contaminadas com secreções corpóreas em lixo comum, em recipientes abertos expostos a insetos, evidenciando o desconhecimento dos profissionais ao risco a que estão expostos ${ }^{5}$.

Observa-se com frequência na literatura o relato de uso de luvas de procedimentos durante todos os atendimentos prestados pelos profissionais da saúde. Entretanto, os demais EPI têm apresentado baixa adesão se comparados às luvas 5 . Dentre os motivos alegados como dificultadores do uso desses equipamentos estão o fato de que alguns deles são de uso coletivo, esquecimento, dificuldade de comunicação com a vítima, indisponibilidade e embaçamento das lentes dos óculos.

Considera-se o relato de indisponibilidade de EPI um problema grave, e, por isso, buscou-se averiguar essa afirmativa. Dessa forma, verificou-se que a indisponibilidade é um fato que ocorre entre os meses de novembro e março, período em que se fecha 0 ano financeiro no Estado e todo o crédito é descentralizado para ser empenhando até final de novembro, abrindo o novo ano financeiro a partir de março, geralmente após o carnaval. Assim, o socorrista se encontra muitas vezes exposto ao material biológico, sem proteção devido às questões administrativas voltadas para a aquisição de material.

Esse fato também foi constatado em um trabalho semelhante realizado com os profissionais do Corpo de Bombeiros de Goiás, em que 36,3\% (16) dos profissionais alegaram falta de material para proteção individual. Entretanto, a justificativa para a indisponibilidade foi uma ausência de planejamento da distribuição destes materiais, pois 0 profissional responsável em repô-los era um membro da equipe que nem sempre verificava o estoque na unidade de resgate ${ }^{5}$. Entretanto, no presente estudo infere-se que tal fato associado à questão financeira administrativa possa ser minimizado com uma possível previsão/planejamento de material antes do fechamento do ano fiscal que contemple um estoque até 0 próximo ano financeiro.

Quanto à cobertura vacinal, quando abordados sobre o número de doses de vacina, os dados obtidos resultam em grande preocupação tendo em vista que a hepatite $B$ tem um alto poder de infectividade após exposição a material biológico: risco estimado entre $6 \%$ e $30 \%$, podendo atingir até $40 \%$, quando inexiste adoção de medidas profiláticas ${ }^{6}$. Assim, quando comparada à hepatite $\mathrm{C}$ e à síndrome da imunodeficiência adquirida (SIDA), cujos riscos de contaminação após acidente percutâneo são, respectivamente de 1,8\% (podendo variar de 1 a 10\%) e de 0,3 a 0,5\%, a hepatite B apresenta maior probabilidade de ser adquirida e é a única passível de prevenção pela imunização ${ }^{6}$. Sua transmissão ocorre por meio do sangue e demais fluidos orgânicos, sendo a doença infecciosa mais comum entre profissionais da saúde do que na população geral, devido ao maior contato com material biológico em decorrência da profissão; por isso, sua imunização é uma exigência para o exercício da profissãa ${ }^{7,13-14}$.

0 fato de $36,4 \%$ dos participantes afirmarem que a realização de exames sorológicos, após o acidente ocupacional, para HIV, hepatite $B$ e hepatite $C$ deve ser feita apenas uma semana após o ocorrido também é preocupante, na medida em que se faz necessário o conhecimento e acompanhamento sorológico com intuito de iniciar medidas profiláticas, capazes de reduzir ou eliminar o risco de desenvolvimento de uma doença.

Quanto aos acidentes, foi necessário incluir nesse item apenas aqueles decorrentes do resgate com envolvimento de fluidos corporais ou materiais cortantes ou perfurantes, uma vez que a quase totalidade dos militares relataram sofrer apenas acidentes por contaminação em águas poluídas.

Apesar de não ter sido averiguada no presente trabalho, a inexistência dos acidentes pode ser justificada pelo fato de que o serviço prestado pelo APH do CBMMG é de suporte básico de vida, o que pressupõe a não realização de procedimentos invasivos.

Todavia, não se descarta a possibilidade de acidentes com materiais perfurantes ou cortantes, visto que esses profissionais têm à disposição bisturis para os atendimentos e estão em risco de se cortarem em ferragens, latarias e vidrarias de veículos. Da mesma forma, a não ocorrência dos acidentes foi registrada entre os profissionais do Corpo de Bombeiros de Goiás, for talecendo a inferência da subestimação destes, ou mesmo sua subnotificaçãa ${ }^{5}$. Outro 
aspecto que merece destaque neste sentido se refere à possibilidade do desconhecimento dos riscos a que estão expostos os profissionais do corpo de bombeiros durante o $\mathrm{APH}$, à negligência dos acidentes por esses profissionais, considerando desnecessária a notificação, por exemplo, de um corte ocorrido na lataria ou ferragens de um veículo.

\section{CONCLUSÕES}

Os profissionais do atendimento pré-hospitalar do corpo de bombeiros demonstraram conhecimento sobre precauções-padrão e noções sobre o risco de infecção após contato direto e indireto com material biológico, embora muitos deles tenham relatado ausência de uma disciplina e/ou palestra que trabalhasse a biossegurança ou segurança da vítima durante a formação profissional. Quanto à adesão às recomendações de biossegurança, evidenciou-se que, em alguns aspectos, os socorristas atendem ao preconizado pela literatura, como 0 descarte de resíduos e o uso de luvas descartáveis, apesar de não representarem a totalidade dos respondentes.

Entretanto, observa-se, como reflexo desse despreparo técnico-científico, a confusão de conceitos gerando atitudes equivocadas, como a crença da capacidade de esterilização das mãos com uso do álcool a 70\%, utilização de água oxigenada nos processos de limpeza da viatura na presença de material biológico e desconhecimento de doses recebidas para hepatite $B$.

No aspecto da formação destes socorristas, inferese também que a abordagem de biossegurança adotada no curso ministrado em todos os níveis de formação da corporação, tem sido insuficiente, superficial e pouco incorporada pelos militares.

Diante dos resultados, espera-se a sensibilização dos profissionais e instituições responsáveis quanto à reavaliação da proposta relacionada à formação dos profissionais do APH, no corpo de bombeiros, na área de biossegurança e saúde ocupacional, à importância das parcerias com universidades e secretarias de saúde, no sentido de manter um programa de qualificação e atualização profissional voltado para a temática em questão, bem como à exigência de vacinação contra hepatite $B$, tétano e difteria conforme recomendação da NR32.

\section{REFERÊNCIAS}

1. Soerensen AA. Acidentes ocupacionais com ênfase ao risco biológico em profissionais do Atendimento Pré-hospitalar móvel [tese de doutorado]. Ribeirão Preto(SP): USP; 2008.
2. Deslandes SF, Souza ER. Atendimento pré-hospitalar ao idoso vítima de violência em cinco capitais brasileiras. Ciênc. saúde coletiva. 2010 set; 15(6): $2775-86$

3. Oliveira AC, Lopes ACS, Paiva MHRS. Acidentes ocupacionais por exposição a material biológico entre a equipe multiprofissional do atendimento pré-hospitalar. Rev. Esc. Enferm. USP. 2009 set; 43(3): 67783.

4. Siegel JD, RhinehartE, Jackson M, Chiarello L; Health Care Infection Control Practices Advisory Committee. Guideline for Isolation Precautions: Preventing Transmission of Infectious Agents in Healthcare Settings. Am J Infect Control. 2007 Dec; 35(10 Suppl 2): S65-164.

5. Florêncio VB, Rodrigues CA, Pereira MS, Souza ACS. Adesão às precauções padrão entre os profissionais da equipe de resgate préhospitalar do Corpo de Bombeiros de Goiás. Rev. eletrônica enferm. [Internet]. 2003 [citado 2011 jan 17]; 5(1): 43-8. Disponível em <http:/ / www. higieneocupacional.com.br/download/adesaoequipevaleria_b_florencio.pdf $>$.

6. Ministério da Saúde (BR). Recomendações para atendimento e acompanhamento de exposição ocupacional a material biológico: HIV e hepatite B e C. Brasilia(DF): Ministério da Saúde; 2004.

7. Lopes ACS, Oliveira AC, Silva JT, Paiva MHRS. Adesão às precauções padrão pela equipe do atendimento pré-hospitalar móvel de Belo Horizonte, Minas Gerais. Cad. saúde pública [periódico na internet]. 2008 jun [citado 2011 jan 17 ]; 24(6): 1387-96. Disponível em < http://www.scielosp.org/scielo.php?script=sci_arttext\&pid=S0102$311 \times 2008000600019 \& \operatorname{lng}=$ en.doi:10.1590/S0102$311 \times 2008000600019>$.

8. Lei Estadual $n^{0} 11.099$, de 18 de maio de 1993. Dispõe sobre a criação do efetivo feminino do corpo de bombeiros. Diário Oficial do Estado, Belo Horizonte (MG), 18 jun 1993.

9. Minas Gerais. Secretaria de Defesa Social. Resolução nº 342, de julho de 2009. Dispõe sobre a criação do módulo I (preparatório) lição 1.2 "0 bem estar do socorrista". Belo Horizonte(MG); 2009.

10. Healthcare Infection Control Practices Advisory Committee (HICPAC). Guideline for disinfection and sterilization in healthcare facilities, 2008 [citado em 2010 mar 09]. Chapel Hill(EUA): HICPAC, 2008. Disponível em: <http://www.cdc.gov/ncidod/dhqp/pdf/guidelines/ Disinfection_Nov_2008.pdf>.

11. Agência Nacional de Vigilância Sanitária/ANVISA(BR). Segurança do Paciente em Serviços de Saúde - Limpeza e Desinfecção de Superfícies [citado em 2011 maio 19]. Brasilia(DF); 2010. 120 p. Disponível em: <http://www2.rio.ri.gov.br/governo/vigilanciasanitaria/manuais/ manual_seguranca_paciente_anvisa_2010.pdf>.

12. World Health Organization. WHO Guidelines on Hand Hygiene in Health Care. Geneva (SUI): WHO; 2009. 
13. Oliveira AC, Paiva MHRS, Paula AO, Gama CS. Hepatitis B vaccine coverage and serological situation among undergraduate medical students exposed to biological material: quantitative analysis. Online braz. j. nurs. [online]. 2010 [citado 2011 fev 15]; 9(3), Disponível em: <http:// uww.objnursing.uff.br/index.php/nursing/article/view/3174>

14. Pinheiro J, Zeitoune RCG. Hepatite B: conhecimento e medidas de biossegurança e a saúde do trabalhador de enfermagem. Esc Anna Nery. 2008 jun; 12(2): 258-64. 


\title{
ANEXO 1
}

\section{QUESTIONÁRIO}

\author{
Algumas informações
}

Número:

- Esta pesquisa tem como objetivo identificar os conhecimentos dos profissionais atuantes no atendimento pré-hospitalar do corpo de bombeiros em relação às recomendações de biossegurança.

- Lembre-se: 0 questionário deve ser respondido individualmente.

- Evite deixar questões em branco, pois sua participação é importante para o sucesso deste trabalho.

- $\quad$ Agradecemos pelo seu tempo e disponibilidade em responder a esta pesquisa.

- $\quad$ Cada questão tem apenas uma alternativa como resposta

1- Categoria profissional: ( ) Subtenente/Sargento ( ) Cabo/Soldado ( ) Outros:

2- Sexo: ( ) Feminino ( ) Masculino

3- Data de nascimento: 1

4 - Idade: anos

5- Possui algum curso de graduação?

a) Sim. Se sim, qual?

b) Não

6- Curso realizado no corpo de bombeiros:

a) Curso de Formação de Soldados (CFSd)/Curso Técnico em Segurança Pública (CTSP): meses

b) Curso de Formação de Sargentos (CFS)/Curso Especial de Formação de Sargentos (CEFS)/Curso Intensivo de Formação de Sargentos (CIFS):__anos__ meses

c) Curso de Aperfeiçoamento de Sargentos (CAS): anos_meses

d) Curso de Formação de Oficiais (CFO)/Curso de Habilitação de Oficiais (CHO)/Curso Especial de Formação de Oficiais (CEFO):__anos meses

7- Tempo de atuação no Corpo de Bombeiros (duração em anos e meses)

8) Durante sua formação no corpo de bombeiros, houve alguma disciplina/palestra específica sobre biossegurança ou segurança da vítima?

a) $\operatorname{Sim}$.

b) Não.

9) Há quanto tempo essa disciplina/palestra foi ministrada?
a) Há menos de 6 meses.
b) Entre 6 meses e um ano
c) Entre 1 ano e dois anos.
d) Há mais de dois anos.
e) Não foi ministrada.

10) Qual o meio que você mais utiliza para sua atualização profissional?
a) Revistas científicas.
b) Computador ou pesquisa em sites eletrônicos.
c) Televisão/jornais/rádio.
d) Participação em treinamentos em serviço, cursos, palestras, simpósios e outros.
e) Nenhum
f) Outro:

Responda as perquntas 11 a 16 com base no conhecimento teórico desenvolvido ao longo do seu curso/formacão.

11) A higienização das mãos com água e sabão é recomendada:

a) Antes e após o contato com a vítima e antes e após remover luvas estéreis ou não-estéreis.

b) Apenas se a mão estiver suada.

c) Somente após o contato com cada vítima.

d) Não sei.

12) $O$ uso de álcool a $70 \%$ está indicado para a fricção das mãos considerando a seguinte característica abaixo descrita.

a) Capacidade de conservar as proteínas das bactérias.

b) Capacidade potencializar a eliminação de sujeira e matéria orgânica das mãos.

c) Inibição do crescimento microbiano.

d) Capacidade de esterilização das mãos.

e) Não sei.

13) A fricção das mãos com álcool $70 \%$ é recomendada em qual das situações abaixo?

a) Na ausência de sujidade visível nas mãos.

b) Somente durante o contato com a mesma vítima.

c) Somente antes de sair da unidade para atender a ocorrência.

d) Não sei.

14) Após o contato do sangue da vítima com a mucosa ocular do profissional, este apresenta algum risco de desenvolver uma infecção?

a) Não, profissionais têm suficiente resistência orgânica.

b) Não, se o profissional for vacinado para hepatite B, C e HIV.

c) Sim, se a vítima apresentar alguma doença infecciosa transmitida pelo sangue.

d) Sim, se a vítima apresentar qualquer doença, independente da forma de transmissão.

e) Não sei. 
15) Dentre as possíveis infecções que podem ser adquiridas devido à natureza do trabalho executado no Atendimento pré-hospitalar estão:

a) Febre amarela, tuberculose, dengue.

b) Hepatite B, hepatite C, AIDS.

c) Sarampo, leishmaniose, coqueluche.

d) Não sei.

16) As precauções padrão (anteriormente denominadas precauções universais) consistem em: a) Usar equipamentos de proteção individual (óculos, máscara, luvas, gorro, capote e sapatos impermeáveis e fechados), lavar as mãos, vacinar contra hepatite B e desprezar material perfurocortante em recipiente de paredes rígidas.

b) Usar máscara facial, propés, friccionar álcool 70\% nas mãos, vacinar contra tétano.

c) Usar avental impermeável, luvas descartáveis e vacinar contra a tuberculose e sarampo.

d) Não sei.

17) Quanto ao lixo produzido após o Atendimento PréHospitalar deve-se:

a) Acondicionar em saco plástico preto devidamente identificado.

b) Desprezar em saco plástico comum devidamente identificado.

c) Acondicionar em saco plástico branco leitoso devidamente identificado.

d) Não sei.

18) Após um acidente de trabalho envolvendo fluídos corporais deve-se:

a) Realizar testes sorológicos para HIV, hepatite B e hepatite $C$ uma semana após o ocorrido, pois é o tempo correspondente ao período de incubação dos vírus citados.

b) Realizar testes sorológicos para HIV, hepatite B e hepatite $C$ no dia do ocorrido, três, seis meses e um ano após o acidente.

c) Não realizar nenhum procedimento, se o teste para HIV da vítima for negativo.

d) Não sei.

Responda as perquntas sequintes com base em suas atitudes no cotidiano de trabalho.

19) Dos equipamentos de proteção individual (EPI) abaixo listados, qual (is) você sente maior dificuldade de usar? Marque quantas opções necessitar

a) Luvas de procedimento.

b) Mascara facial.

c) Óculos de segurança.

d) Capote/avental.

e) Nenhum

f) Outro:

Responda as questões 20 a 23 conforme suas dificuldades apontadas na questão 19. Caso não apresente dificuldades na utilização de EPI. continue a partir da questão 24.

20) A dificuldade de usar luvas se deve a:

a) Indisponibilidade do seu tamanho, na viatura.

b) Ausência de tempo durante o atendimento.

c) Esquecimento.

d) Perda de sensibilidade das mãos. e) Seu uso é irrelevante.

f) Outro:

21) A dificuldade de usar máscara se deve a:

a) Embaçamento das lentes dos óculos.

b) Sensação de sufocamento.

c) Dificuldade de comunicação com a vítima.

d) Indisponibilidade na viatura.

e) Ausência de tempo durante o atendimento.

f) Esquecimento.

g) Seu uso é irrelevante.

h) Outro:

22) A dificuldade de utilizar óculos se deve a:

a) Incompatibilidade com a máscara e crença de que ela é mais importante.

b) Indisponibilidade na viatura.

c) Seu uso ser coletivo.

d) Dificuldade de avaliação da vítima.

e) Ausência de tempo durante o atendimento.

f) Esquecimento.

g) Seu uso é irrelevante.

h) Outro:

23) A dificuldade de utilizar capotelavental se deve a:

a) Esquecimento.

b) Indisponibilidade na viatura.

c) Ausência de tempo durante o atendimento.

d) Seu uso é irrelevante.

e) Outro:

24) Durante procedimentos em que haja risco de se expor a contato com líquidos corporais da vítima, com qual freqüência você utiliza as luvas descartáveis?

a) Sempre.

b) Na maioria das vezes.

c) Algumas vezes.

d) Nunca.

25) Em relação à vacina para hepatite $B$, quantas doses você recebeu?

a) Nenhuma dose.

b) Uma dose.

c) Duas doses.

d) Três doses.

e) Não sei.

26) Qual é o procedimento de limpeza mais adotado por você, em caso de presença de sujidade das superfícies da viatura com materiais biológicos (sangue, saliva, sêmen, secreção vaginal ou do ânus, liquido amniótico), após o atendimento à vítima?

a) Limpeza das superfícies com água e sabão.

b) Limpeza das superfícies com água e sabão, seguida de álcool $70 \%$.

c) Limpeza das superfícies imediata com álcool $70 \%$.

d) Limpeza das superfícies com água oxigenada a $3 \%$.

e) Limpeza das superfícies com hipoclorito de sódio a $1 \%$.

f) Outro:

27) Nos últimos doze meses, você sofreu algum acidente ocupacional envolvendo material biológico (sangue, saliva, sêmen, secreção vaginal ou do ânus, 
liquido amniótico) durante o Atendimento préhospitalar?
a) $\operatorname{Sim}$
b) Não

Se a resposta à questão 27 for AFIRMATIVA, prossiga respondendo as questões 28 a 40 Caso seja NEGATIVA, sua participação finaliza aqui! Obrigado

28) Quantas vezes você sofre acidente ocorreram no ano de $\mathbf{2 0 0 9}$ até o presente momento?

a) Uma vez.

b) Duas vezes.

c) Três vezes.

d) Outro:

Caso tenha sofrido mais de um acidente, favor responder as próximas perguntas baseando-se no último acidente.

29) $O$ que causou o acidente?

a) Lesão provocada por material perfurocortante (ex.: lâminas, agulhas, bisturi, lancetas).

b) Contato entre fluidos corporais e a mucosa oral.

c) Contato entre fluidos corporais e a mucosa ocular.

d) Lesão provocada por material perfurante (ex:

lataria de automóveis).

e) Outro:

30) Procedimento/evento que produziu a exposição:

a) Vítima espirrou/tossiu/vomitou.

b) Cuidado com ferimentos.

c) Parto vaginal.

d) Colocação/remoção/manipulação de cateteres/ tubos (por exemplo, cânula oro-traqueal).

e) Outro:

31) Indique a parte do seu corpo que foi exposta/ atingida no acidente:

a) Mão/dedo.

b) Olhos.

c) Boca/ Nariz.

d) Outros:

32) Em caso de acidente percutâneo envolvendo material perfurocortante ou perfurante), determine a profundidade da lesão:

a) Superficial. Exemplo: arranhão com pouco ou nenhum sangramento.

b) Moderada. Exemplo: perfurou a pele, a lesão sangrou.

c) Profunda. Exemplo: penetração intramuscular.

d) Indeterminada/ desconhecida.

e) Não foi acidente percutâneo.

33) Em caso de acidente envolvendo membrana mucosa (por exemplo, boca, olhos) ou pele determine o volume aproximado do material:

a) Pequeno. Exemplo: poucas gotas.

b) Grande. Exemplo: grande respingo de sangue.

c) Indeterminado/ desconhecido.

d) Não sei precisar a quantidade.

e) Não foi acidente envolvendo membrana mucosa ou pele.

34) Em qual período do dia ocorreu o acidente?

a) Entre 06:00 e 12:00 hs. b) Entre 12:01 e 18:59 hs.

c) Entre 19:00 e 00:00 hs.

d) Entre 00:01 e 05:59 hs.

35) No momento do acidente, você estava escalado para trabalhar em qual unidade?

a) Unidade de salvamento.

b) Unidade de resgate.

c) Auto-bomba.

d) Outro:

36) Qual equipamento de proteção individual (EPI) estava sendo utilizado por você no momento do acidente?

a) Nenhum.

b) EPI completo (luvas, capote, máscara, óculos, gorro, sapatos fechados).

c) EPI incompleto. Especificar:

d) Não me lembro.

37) Após o acidente qual das atitudes abaixo você tomou?

a) Lavou o local atingido com água e sabão em caso de acidente percutâneo ou cutâneo ou lavou com água ou soro fisiológico $0,9 \%$ em caso de exposição de mucosas.

b) Esfregou álcool no local atingido.

c) Lavou o local atingido somente com água.

d) Esfregou água oxigenada no local.

e) Não fez nada.

f) Outro:

38) Após o acidente de trabalho você foi examinado por um médico?

a) $\mathrm{Sim}$.

b) Não.

c) Não me lembro.

39) Após o acidente de trabalho você procurou a Sessão de Assistência à Saúde (SAS) e foi emitida a Comunicação de Acidente (CA)?
a) Sim.
b) Não.
c) Não me lembro

40) Após o acidente foi feito o teste rápido para HIV na vítima?

a) $\mathrm{Sim}$.

b) Não.

c) Não me lembro. 